\title{
EDITORIAL
}

\section{Cardiac resynchronization therapy}

Cardiac resynchronization therapy (CRT) is a relatively new but established therapy for patients with symptomatic heart failure resulting from systolic dysfunction. CRT is achieved by simultaneously pacing both the left and right ventricles. Theoretically, biventricular pacing resynchronizes the timing of global left ventricular depolarization and as a result improves mechanical contractility and mitral regurgitation. Several recently published clinical trials demonstrated clinical improvement when selected patients with systolic ventricular dysfunction and heart failure were treated with CRT. ${ }^{1-6}$

Conduction delay, as manifested by a prolonged QRS complex duration, is common among patients with systolic dysfunction and heart failure and is associated with an increased prevalence of mechanical dyssynchrony, as opposed to patients with a narrow QRS complex. Cardiac dyssynchrony results in a decrease in stroke volume, facilitation of mitral regurgitation, increased wall stress, and delayed relaxation. The primary objective of CRT is restoration of a more normal ventricular activation pattern. Secondarily, CRT allows optimization of the atrioventricular interval for patients in sinus rhythm. ${ }^{7,8}$

CRT has been shown to improve functional status as demonstrated by the improve in 6-minute walk test, increase in peak oxygen uptake, decrease in the New York Heart Association (NYHA) classification system, decrease in hospitalization for decompensated heart failure, and improve in health-related quality of life as assessed by the Minnesota Living with Heart Failure questionnaire. As with most therapeutic interventions, not all patients improve with CRT. Although improvements in survival have not been demonstrated with CRT alone, a recent meta-analysis suggested a trend toward improvement. ${ }^{9}$ The largest and most recent randomized trial of CRT demonstrated a significant reduction in the combined end point of all-cause mortality and hospitalization. ${ }^{6}$

On the basis of the inclusion criteria and the results of many studies, a high level of evidence supports CRT in patients with systolic dysfunction and heart failure resulting from either ischemic or nonischemic cardiomyopathy who have a left ventricular ejection fraction (LVEF) 0.35, are in NYHA functional class III or IV, are on maximal medical therapy, have a QRS complex duration $>120 \mathrm{~ms}$, and are in sinus rhythm. ${ }^{1-6}$ Some trials suggest that CRT may be of benefit for other clinical scenarios in addition to this patient profile. Two randomized multicenter trials assessed the benefit of CRT in patients with NYHA functional class II symptoms despite medical therapy, a depressed LVEF, a wide QRS duration, and an indication for implantable defibrillator therapy. 5,10 In these studies, CRT demonstrated functional improvement as well as left ventricular remodeling.

The role of CRT in other groups of patients with heart failure resulting from systolic dysfunction, including patients with atrial fibrillation or a wide QRS morphology on the basis of right ventricular pacing, is unclear. Preliminary data from a large study and results from a few small studies suggest that in patients with atrial fibrillation and complete atrioventricular block, CRT may provide functional improvement when compared with right ventricular pacing. ${ }^{11-14}$ Among patients with a cardiomyopathy, sinus rhythm, and an indication for an implantable defibrillator but not permanent pacing, right ventricular pacing precipitates and has a negative impact on heart failure. ${ }^{15}$ The results of this study 15 suggest that right ventricular pacing is not optimal in this group of patients and that biventricular pacing may be better; however, there are no prospective data to support this approach. The published randomized CRT studies have used QRS complex duration as a surrogate marker for dyssynchrony. ${ }^{1-6}$ In the future, we may be able to identify patients with ventricular dyssynchrony and who will respond to CRT with the use of tissue Doppler or other echocardiographic or visualization techniques..$^{15}$

The results of numerous randomized clinical trials provide the necessary data to identify appropriate patients for CRT. Optimal candidates for CRT have a dilated cardiomyopathy on an ischemic or nonischemic basis, an LVEF 0.35, a QRS complex $>120 \mathrm{~ms}$, and sinus rhythm, and are NYHA functional class III or IV despite maximal medical therapy for heart failure. In general, these patients are treated with a CRT device that also has defibrillation capabilities. A variety of unresolved issues include the role of CRT for patients with NYHA functional class II symptoms or with atrial fibrillation, prospective identification of responders to CRT, and the role of CRT in other categories of patients. In our setting we implant CRT for above-mentioned indications. The main hurdles in our setting are cost of the device, longevity of the patients and availability of the device. This is only one aspect of the treatment of heart failure but definitely a promising solution for refractory heart failure patients.

\section{Prof. Md. Abu Siddique PhD}

Professor of Cardiology

Bangabandhu Sheikh Mujib Medical University

Shahbag, Dhaka.

E-mail: drabusiddique@yahoo.com

\section{Dr. Mohammad Salman MD}

Department of Cardiology

Bangabandhu Sheikh Mujib Medical University

Shahbag, Dhaka.

\section{References}

1. Cazeau S, Leclercq C, Lavergne T, Walker S, Varma C, Linde C, Garrigue S, Kappenberger L, Haywood GA, Santini M, Bailleul C, Daubert JC; Multisite Stimulation in Cardiomyopathies (MUSTIC) Study Investigators. Effects 
of multisite biventricular pacing in patients with heart failure and intraventricular conduction delay. $\mathrm{N}$ Engl $\mathrm{J}$ Med. 2001; 344: 873-80.

2. Auricchio A, Stellbrink C, Sack S, Block M, Vogt J, Bakker P, Huth C, Schondube F, Wolfhard U, Bocker D, Krahnefeld $\mathrm{O}$, Kirkels H; Pacing Therapies in Congestive Heart Failure (PATH-CHF) Study Group. Long-term clinical effect of hemodynamically optimized cardiac resynchronization therapy in patients with heart failure and ventricular conduction delay. J Am Coll Cardiol. 2002; 39: 2026-33.

3. Abraham WT, Fisher WG, Smith AL, Delurgio DB, Leon AR, Loh E, Kocovic DZ, Packer M, Clavell AL, Hayes DL, Ellestad M, Trupp RJ, Underwood J, Pickering F, Truex C, McAtee P, Messenger J; MIRACLE Study Group. Multicenter InSync Randomized Clinical Evaluation. Cardiac resynchronization in chronic heart failure. N Engl J Med. 2002; 346: 1845-53.

4. Young JB, Abraham WT, Smith AL, Leon AR, Lieberman R, Wilkoff B, Canby RC, Schroeder JS, Liem LB, Hall S, Wheelan K; Multicenter InSync ICD Randomized Clinical Evaluation (MIRACLE ICD) Trial Investigators. Combined cardiac resynchronization and implantable cardioversion defibrillation in advanced chronic heart failure: the MIRACLE ICD Trial. JAMA. 2003; 289: 2685-94.

5. Higgins SL, Hummel JD, Niazi IK, Giudici MC, Worley SJ, Saxon LA, Boehmer JP, Higginbotham MB, De Marco T, Foster E, Yong PG. Cardiac resynchronization therapy for the treatment of heart failure in patients with intraventricular conduction delay and malignant ventricular tachyarrhythmias. J Am Coll Cardiol. 2003; 42: 1454-59.

6. Bristow MR, Saxon LA, Boehmer J, Krueger S, Kass DA, De Marco T, Carson P, DiCarlo L, DeMets D, White BG, DeVries DW, Feldman AM; Comparison of Medical Therapy, Pacing, and Defibrillation in Heart Failure (COMPANION) Investigators. Cardiac-resynchronization therapy with or without an implantable defibrillator in advanced chronic heart failure. N Engl J Med. 2004; 350: 2140-50.

7. Nelson GS, Curry CW, Wyman BT, Kramer A, Declerck J, Talbot M, Douglas MR, Berger RD, McVeigh ER, Kass DA. Predictors of systolic augmentation from left ventricular preexcitation in patients with dilated cardiomyopathy and intraventricular conduction delay. Circulation. 2000; 101: 2703-09

8. Nelson GS, Berger RD, Fetics BJ, Talbot M, Spinelli JC, Hare JM, Kass DA. Left ventricular or biventricular pacing improves cardiac function at diminished energy cost in patients with dilated cardiomyopathy and left bundle-branch block. Circulation. 2000; 102: 3053-59.

9. Bradley DJ, Bradley EA, Baughman KL, Berger RD, Calkins H, Goodman SN, Kass DA, Powe NR. Cardiac resynchronization and death from progressive heart failure: a meta-analysis of randomized controlled trials. JAMA. 2003; 289 : 730-40.

10. Abraham WT, Young JB, Leon AR, Adler S, Bank AJ, Hall SA, Lieberman R, Liem LB, O'Connell JB, Schroeder JS, Wheelan KR; Multicenter InSync ICD II Study Group. Effects of cardiac resynchronization on disease progression in patients with left ventricular systolic dysfunction, an indication for an implantable cardioverter-defibrillator, and mildly symptomatic chronic heart failure. Circulation. 2004; 110: 2864-68.

11. Wilkoff BL, Cook JR, Epstein AE, Greene HL, Hallstrom AP, Hsia H, Kutalek SP, Sharma A; Dual Chamber and VVI Implantable Defibrillator Trial Investigators. Dual-chamber pacing or ventricular backup pacing in patients with an implantable defibrillator: the Dual Chamber and VVI Implantable Defibrillator (DAVID) Trial. JAMA. 2002; 288: 3115-23.

12. Leclercq C, Walker S, Linde C, Clementy J, Marshall AJ, Ritter P, Djiane P, Mabo P, Levy T, Gadler F, Bailleul C, Daubert JC. Comparative effects of permanent biventricular and right-univentricular pacing in heart failure patients with chronic atrial fibrillation. Eur Heart J. 2002; 23: 1780-87

13. Leon AR, Greenberg JM, Kanuru N, Baker CM, Mera FV, Smith AL, Langberg JJ, DeLurgio DB. Cardiac resynchronization in patients with congestive heart failure and chronic atrial fibrillation: effect of upgrading to biventricular pacing after chronic right ventricular pacing. J Am Coll Cardiol. 2002; 39: 1258-63

14. Linde C, Leclercq C, Rex S, Garrigue S, Lavergne T, Cazeau S, McKenna W, Fitzgerald M, Deharo JC, Alonso C, Walker $\mathrm{S}$, Braunschweig F, Bailleul C, Daubert JC. Long-term benefits of biventricular pacing in congestive heart failure: results from the MUltisite STimulation in cardiomyopathy (MUSTIC) study. J Am Coll Cardiol. 2002; 40: 111-18.

15. Doshi R, Daoud E, Fellows C, Turk K, Duran A, Hamden M, and the investigators of the PAVE study. Mortality and congestive heart failure in the PAVE study. Europace. 2004; 6 (suppl 1): 92. Abstract 115/1. 